\title{
Erratum to: Calculation of Direct Drive Targets for Megajoule Laser Facilities with Radiation in the Second and Third Harmonics of Nd Laser
}

\author{
E. S. Bakurkina ${ }^{a}$, V. E. Chernyakov ${ }^{a}$, N. G. Karlykhanov ${ }^{a}$, I. A. Khimich ${ }^{a}$, \\ V. A. Lykov ${ }^{a, *}$, and G. N. Rykovanov ${ }^{a}$ \\ ${ }^{a}$ Federal State Unitary Enterprise "Russian Federal Nuclear Center-Zababakhin All-Russian Research Institute \\ of Technical Physics”, Snezhinsk, 456770 Russia \\ *e-mail:v.a.lykov@vniitf.ru
}

Received December 2, 2020; revised December 6, 2020; accepted December 14, 2020

DOI: $10.1134 / \mathrm{S} 1063778820120030$

The quantity $G_{q c}$ which is defined right after the formula (2) in the right column on page 1349 should read as follows:

$$
G_{q c}=1.7 \times 10^{3} \frac{\langle Z\rangle}{\left\langle Z^{2}\right\rangle}\left(\frac{L_{q c}}{\lambda}\right) \frac{I_{q c} \lambda^{2}}{T_{e, q c}} \xi_{q c} .
$$

The formula (4) presented in the left column on page 1350 should read as follows:

$$
A_{\mathrm{SRS}}=\left\{\begin{array}{l}
0.125 f_{\mathrm{SRS}}\left\{1-\exp \left[-\left(G_{\mathrm{SRS}}^{1 / 3}-1\right)\right]\right\} \\
\text { if } \quad G_{\mathrm{SRS}} \geq 1 \\
0, \quad \text { if } \quad G_{\mathrm{SRS}}<1
\end{array}\right.
$$

The first sentence of the second paragraph in the right column on page 1357 should be the following: According to these calculations, a glass ablator allows one to almost eliminate fast electrons for laser radiation with $\lambda=0.35 \mu \mathrm{m}$ (see rows 5 and 7 in Tables 6 and 7 ). The last sentence of the same paragraph should be the following: In this case, according to the calculations (see row 5 in Tables 6 and 7), the ignition margin may reach $W_{Q}=1.7$ and the fusion energy yield may be $E_{\text {fus.e }}^{*} \approx 42 \mathrm{MJ}$.
The original article can be found online at https://doi.org/10.1134/S1063778819100028 